\title{
Ultrastructural study of meronts and gamonts of Choleoeimeria rochalimai (Apicomplexa: Eimeriidae) developing in the gall bladder of the gecko Hemidactylus mabouia from Brazil
}

\author{
Ilan Paperna ${ }^{1}$ and Ralph Lainson ${ }^{2}$ \\ ${ }^{1}$ Department of Animal Sciences, Faculty of Agriculture of the Hebrew University of Jerusalem, Rehovot 76-100, Israel; \\ ${ }^{2}$ Department of Parasitology, Instituto Evandro Chagas, Caixa Postal 1128, Belém 66090-000, Pará, Brazil
}

Key words: Coccidia, Choleoeimeria rochalimai, fine structure, gall bladder epithelium, Hemidactylus mabouia, Brazil

\begin{abstract}
Endogenous development of Choleoeimeria rochalimai (Carini et Pinto, 1926) Lainson et Paperna, 1999 in the gall bladder of Hemidactylus mabouia (Moreau de Jonnes, 1818) from Belém, Brazil is reported at the fine structural level. Meronts and gamonts develop in the epithelial cells of the gall bladder. Infected cells become enlarged and displaced above the epithelial layer. Developing merozoites, dividing meronts and succession of developing microgamonts from initial nuclear division up to final microgamete differentiation are described. In addition to wall forming bodies, mature macrogamonts possess a large inclusion or cisterna with fine granular contents.
\end{abstract}

Oocysts of eimeriid coccidia developing in the gall bladder of reptiles are ellipsoidal to cylindrical. Their sporocysts, which open along a longitudinal suture, sporulate and also sometimes release their sporozoites while still within the gall bladder (Paperna and Landsberg 1989a). Endogenous development in the biliary epithelium, of all those species so far investigated, involves a characteristic hypertrophy and resulting displacement of the infected host cell. Paperna and Landsberg (1989a) suggested the separation of these gall bladder coccidia, which differ conspicuously from all gut inhabiting coccidia of reptilian, avian and mammalian hosts, into their own genus Choleoeimeria.

In a recent paper (Lainson and Paperna 1999) we redescribed Eimeria rochalimai Carini et Pinto, 1926 from the house-gecko Hemidactylus mabouia (Moreau de Jonnes, 1818) and transferred it to the genus Choleoeimeria Lainson et Paperna, 1999. Choleoeimeria rochalimai coexisted with Eimeria boveroi and Isospora hemidactyli in the same host specimens (Lainson and Paperna 1999). In the present communication, we describe the fine structure of meronts and gamonts of $C$. rochalimai and compare it with that of previously described reptilian gall bladder coccidia, C. chalcides (Daszak et al. 1988) and C. turcicus (Paperna and Landsberg 1989b).

\section{MATERIALS AND METHODS}

Hemidactylus mabouia were from Belém, Pará, North Brazil, and the same used previously (Lainson and Paperna 1999). Infection was detected by demonstration of oocysts in the faeces. Positive lizards were then killed with chloroform and infection in the gall bladder verified by microscopic examination of bile collected by puncturing the gall bladder with a finely pointed glass pipette.

The gall bladder wall was fixed in $2.5 \%$ glutaraldehyde in cacodylate buffer $(0.1 \mathrm{M}, \mathrm{pH} 7.4)$ for $24 \mathrm{~h}$ at $4^{\circ} \mathrm{C}$, rinsed repeatedly in the same buffer, post-fixed in $1.0 \%$ osmium tetroxide in the same buffer for one hour and, after rinsing in buffer, dehydrated in graded ethyl alcohols and embedded in Agar 100 medium (Agar Scientific, Ltd., U.K.). Thin sections, cut on a Reichert Ultracut microtome with a diamond knife, were stained on grids with uranyl acetate and lead citrate, and examined with a JEOL $100 \mathrm{CX}$ transmission electron microscope.

\section{RESULTS}

Infected host cells are enlarged, maintain cytoplasmic integrity, and retain a nucleus of normal size; the surface microvilli, however, are sparse (Fig. 1). The lumen of the parasitophorous vacuole (PV) is filled with globules and fragments of variable size and consistency (Figs. 1, 2). These persist, though in lesser quantities, to the termination of endogenous development.

Invading merozoites contain numerous micronemes and a few rhoptries, and are $3.6 \times 1.8 \mu \mathrm{m}$ in size (Fig. 1). Larger merozoites of $10 \times 3.6 \mu \mathrm{m}$ (Figs. 1, 2), evidently in transition to meronts have a very small apical complex with several short rhoptries, a few scattered micronemes and a number of electron-dense globules. Their pellicule is already, in part, transformed into a single-membrane wall characteristic of meronts (Figs. 1, 2). The cytoplasm also contains electron-dense globules of different sizes, which also occur in variable numbers in the proceeding stages. 

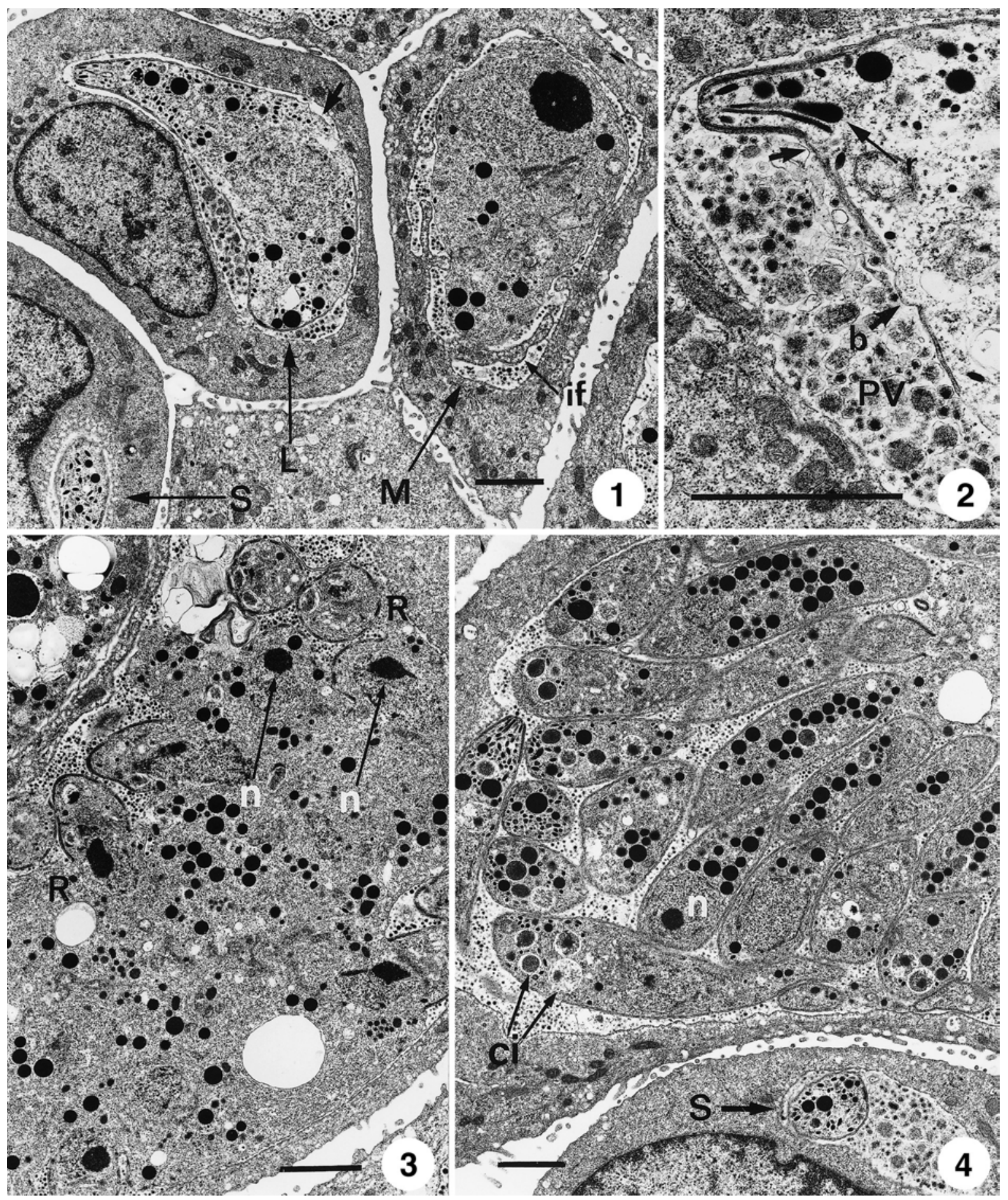

Figs. 1-4. Choleoeimeria rochalimai in the gall bladder epithelial cells of the gecko Hemidactylus mabouia. Fig. 1. Early stages: small, invading merozoite (S), larger merozoite in transition to meront (L) and young macrogamont (M); arrow points to the transformation of the pellicule to a single unit plasmalemma; if - intravacuolar fold. Fig. 2. Enlarged view of a merozoite committed to merogony, the pellicule transforms into a single unit cell wall (b and arrow) and the parasitophorous vacuole (PV) is filled with particulate material; fine arrow - rhoptry. Fig. 3. Early dividing meront, with the nuclei of the emerging merozoites (R) containing a large nucleolus (n). Fig. 4. Divided meront: the merozoite nuclei contain a large nucleolus (n), and vacuolar inclusions (ci). Below is a cross-section of a small merozoite (S) within its PV, filled by flocculate contents. Scale bars $=2 \mu \mathrm{m}$. 


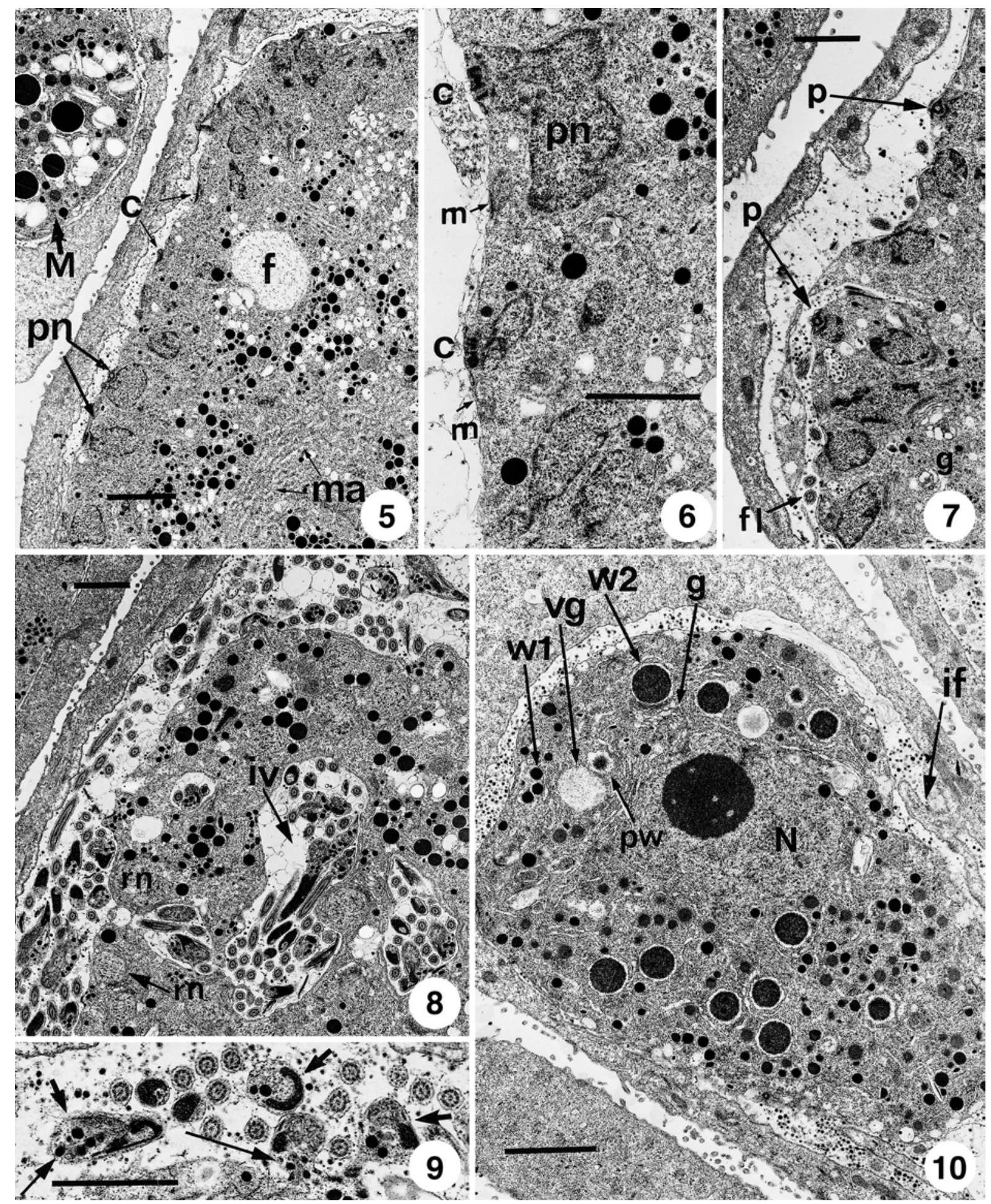

Figs. 5-9. Stages in the production of Choleoeimeria rochalimai microgametes. Fig. 5. Nuclei (pn) arranged around the periphery of a microgamont; c - centrioles; $\mathrm{f}$ - food vacuole; $\mathrm{M}$ - macrogamont; ma - mitochondrial plates. Fig. 6. Enlarged view of the nuclear division (pn); $\mathrm{c}$ - centrioles; $\mathrm{m}$ - mitochondrion. Fig. 7. Onset of microgamete formation; fl - flagellum; $\mathrm{g}$ - Golgi apparatus; $\mathrm{p}$ - emerging microgamete. Fig. 8. Mature differentiated microgamont; iv - infold (invagination) of the microgamont; rn - residual nuclei. Fig. 9. Enlarged view of microgametes (bold arrows) with electron-dense globules (fine arrows). Fig. 10. Premature Choleoeimeria rochalimai macrogamont; $\mathrm{g}$ - Golgi apparatus; if - intravacuolar fold; $\mathrm{N}$ - nucleus; pw - consolidating WFB; vg - forming granular cisterna; w1 - type 1 WFB; w2 - type 2 WFB. Scale bars $=2 \mu \mathrm{m}$. 

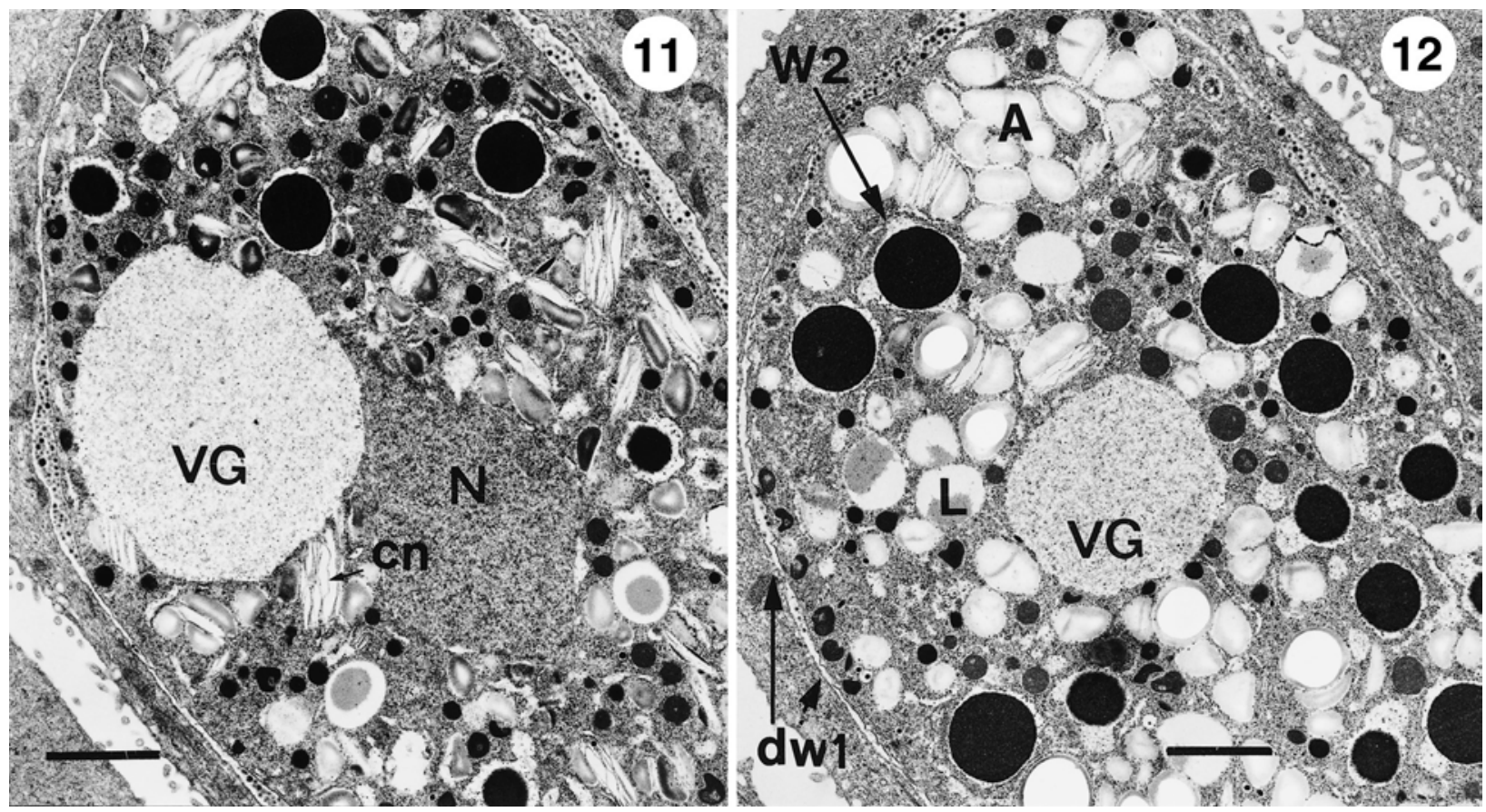

Figs. 11-12. Choleoeimeria rochalimai zygotes. Fig. 11. Mature macrogamont (early zygote); cn - canaliculi; N - nucleus; VG granular cisterna (vacuole). Fig. 12. Later stage zygote; A - amylopectin granules; dw1 - disintegrating WFB1; L - lipid vacuole; W2 - type 2 WFB. Scale bars $=2 \mu \mathrm{m}$.

Merogony is exogenous (exopolygenous) (Fig. 3). Cross-sections (Fig. 4) reveal only a fraction of the 100 or more merozoites produced (see Lainson and Paperna 1999) and which measure 8.7-9.6 × 2.4-3.4 $\mu \mathrm{m}$ (of a same cross-section dimension as the invading merozoites, Fig. 4). In addition to the electron-dense globules, merozoites also contain vacuolar (or cisternal) inclusions of a granular substance with variable density. The dense central nucleolus seen in nuclei of some merozoites suggests that the division products are destined to develop into macrogamonts (Fig. 4).

The differentiation process of the microgamont is shown in Figs. 5-8. Immature microgamonts have peripherally arranged nuclei, and a homogenous nucleoplasm devoid of a distinct nucleolus (Figs. 5, 6). Two centrioles occur beneath the cell wall in the vicinity of each nucleus (Fig. 6). Microgamonts contain numerous electron-dense globules, vacuoles, several mitochondrial aggregates ("Plaque mitochondrial", Porchet-Hennere and Richard 1971 ), and a large inclusion with sparse flocculent contents (perhaps a food vacuole, Fig. 5). The differentiating microgamete nuclei develop a conspicuous, dense chromatin margin and are accompanied by a large Golgi apparatus (Fig. 7). Microgametes emerge along the outer rims of the mature microgamont (of an overall diameter of $31 \mu \mathrm{m}$ ), and along deep infolds. The cytoplasm contains many residual nuclei (Fig. 8). The microgamete cytoplasm contains conspicuous electron-dense granules (Fig. 9), possibly disaggregates of the electron-dense globules from the microgamont's cytoplasm.

Young macrogamonts, $9 \times 5 \mu \mathrm{m}$ in size, are recognised by a nucleus of homogenous nucleoplasm with a large central nucleolus; adjacent to the nucleus there is a paragolgi-like ad-nuclear organ. The cytoplasm contains a few electron-dense globules and mitochondria (Fig. 1). The PV of young as well as mature macrogamonts forms intravacuolar folds of various sizes (Figs. 1, 10).

Macrogamonts are approximately $15 \times 11 \mu \mathrm{m}$ in size and contain numerous small type 1 wall-forming bodies (WFB1) and fewer, larger type 2 WFB which are lodged in endoplasmic reticulum (ER) cisternae (Fig. 10). An extensive network of ER is particularly conspicuous around the nucleus and in the vicinity of WFB2s. Mature, apparently fertilised macrogamonts (zygotes, Figs. 11, 12) are $15-21 \times 10-18 \mu \mathrm{m}$ in size. Their cytoplasm is filled with amylopectin granules together with somewhat fewer lipid vacuoles and many canaliculi. A membrane-bound body of sparse granular content ("granular cisterna", Paperna and Landsberg 1989b), initially seen in the on-growing macrogamont (Fig. 10), reaches the size of the zygote nucleus (Figs. $11,12)$. 


\section{DISCUSSION}

This is the third published account of the ultrastructure of species of Choleoeimeria developing in the gall bladder epithelium of reptilian hosts. The fine structural features of the presently described species are very similar to those of Choleoeimeria turcicus from Hemidactylus turcicus described by Paperna and Landsberg (1989b) and with those of four other species of this genus from geckoes and another from Agama, (Paperna, unpublished). Probert et al. (1988) described a coccidian in the gall bladder of the skink Chalcides ocellatus as Tyzzeria chalcides, and the ultrastructure of its gamogonic stages was reported by Daszak et al. (1989). Paperna and Landsberg (1989a) placed this coccidian in the genus Choleoeimeria. In 1994, Ball et al. amended the name of this parasite to Eimeria chalcides.

The general ultrastructure of Choleoeimeria chalcides conforms with that found in the other species of the genus, although detailed comparison is made difficult due to the processing quality of the images of Daszak et al. (1989). In addition, we disagree with these authors' interpretation (fig. 1b) regarding loss of the inner wall of the parasite, which is more likely a consolidation of the wall boundary by ER contribution (Jones and Hirsch 1972, Paperna and Lainson 1999), and their identification of type 1 and type 2 wallforming bodies (figs. 1g, 2c).

Endogenous development of coccidia infecting reptilian hosts takes place in a variety of tissues and accordingly assumes diverse forms of associations with the host cell: i.e. a conventional form of intracytoplasmic development and epicytoplasmic development in cells of the intestinal mucosa (Paperna 1989, Lainson and Paperna 1999, Paperna and Lainson 1999), development in hypertrophic host cells of the gall bladder (Paperna and Landsberg 1989b, present study) and the specialised development of Eimeria gastrosauris in the stomach epithelium (Paperna 1993). Arguments for regarding these coccidians with these different forms of development as representatives of separate genera have been discussed elsewhere (Paperna and Landsberg 1989a, Lainson and Paperna 1999).

Within each of these groups, all available data (including the senior author's unpublished observations) conform to a fairly unified pattern in fine structure. The bivalved sporocysts of Choleoeimeria spp. are reminiscent of Goussia species common in piscine hosts, but Choleoeimeria has the two types of true wallforming bodies in the macrogamonts, and thus conforms with the reptilian (or terrestrial host) pattern rather than with the piscine fine structural pattern (Paperna 1995).

Two generations of merozoites apparently exist in the development of $C$. rochalimai. However, an earlier stage of binary fission seen in C. turcicus (Paperna and Landsberg 1989b) could not be found. Inclusions filled with fine granular substance have been reported in $C$. turcicus macrogamonts (as "granular cisterna") and small inclusion have been seen in Eimeria boveroi (Paperna and Lainson 1999). Similar large inclusions are reported in Schellackia cf. agamae, these, however, contain an electron-dense substance which fragments gradually into fine material as the macrogamont develops into an oocyst (Ostrovska and Paperna 1987). It has been suggested that these organelles are precursors of the mature oocyst refractile bodies (Paperna 1992).

\section{REFERENCES}

BALL S.J., DASZAK P., PROBERT A.J. 1994: Nomenclatural correction - Eimeria chalcides (Probert, Roberts \& Wilson, 1988) n. comb. for Tyzzeria chalcides (Apicomplexa: Eimeriidae). Syst. Parasitol. 29: 75-77.

DASZAK P., PROBERT A.J., RUNHAM N.W., WILSON I.B. 1989: Ultrastructural observations on the gametocytic stages of the coccidium Tyzzeria chalcides Probert, Roberts \& Wilson 1988 from the ocellated skink Chalcides ocellatus. J. Protozool. 36: 299-303.

JONES T.C., HIRSCH J.C. 1972: The interaction between Toxoplasma gondii and mammalian cells. II. Absence of lysosomal fusion with phagocytic vacuoles containing living parasites. J. Exp. Med. 136: 1173-1195.

LAINSON R., PAPERNA I. 1999: Some coccidia from the gall-bladder and intestine of the teiid lizard Ameiva ameiva ameiva and the gecko Hemidactylus mabouia in north Brazil. Parasite 6: 151-162.

OSTROVSKA K., PAPERNA I. 1987: Fine structure of gamont stages of Schellackia cf. agamae (Lankester- ellidae, Eucoccidia) from the starred lizard Agama stellio. Parasitol. Res. 73: 492-499.

PAPERNA I. 1989: Ultrastructure of Eimeria (s.1.) sp. infecting the microvillar zone of the intestinal epithelium of geckoes. Ann. Parasitol. Hum. Comp. 64: 89-99.

PAPERNA I. 1992: Ultrastructural studies on oocysts, sporulation and sporozoites of Schellackia cf. agamae from the intestine of the starred lizard Agama stellio. Int. J. Parasitol. 22: 361-368.

PAPERNA I. 1993: Ultrastructural study of Eimeria gastrosauris, a coccidium from the stomach epithelium of Australian geckoes. Ann. Parasitol. Hum. Comp. 68: 7075.

PAPERNA I. 1995: Ultrastructure and developmental affinities of piscine coccidia. Dis. Aquat. Org. 22: 67-76.

PAPERNA I., LAINSON R. 1999: The ultrastructure of some endogenous stages of the coccidian Eimeria boveroi Carini \& Pinto 1926 in the gut epithelial cells of the gecko Hemidactylus mabouia from Brazil. Parasite 6: 237-242. 
PAPERNA I., LANDSBERG J.H. 1989a: Description and taxonomic discussion of eimerian coccidia from African and Levantine geckoes. S. Afr. J. Zool. 24: 345-355.

PAPERNA I., LANDSBERG J.H. 1989b: Fine structure of endogenous stages of Eimeria turcicus developing in gall bladder epithelium of the gecko Hemidactylus turcicus $\mathrm{S}$. Afr. J. Zool. 24: 251-259.
PORCHET-HENNERÉ E., RICHARD A. 1971: La sporogènese chez la coccidie Aggregata eberti. Étude en microscope électronique. J. Protozool. 18: 614-628.

PROBERT A.J., ROBERTS A.H., WILSON I.B. 1988: Tyzzeria chalcides n. sp. from the ocellated skink, Chalcides ocellatus. J. Protozool. 35: 211-213. 